\title{
Simulation of the System of Repairs of Apartment Buildings
}

\author{
Serafima Sokova* and Vladimir Kalinin \\ Moscow State University of Civil Engineering", Yaroslavskoe shosse, 26, Moscow, 129337, Russia
}

\begin{abstract}
: the main issue of the study is the problem of improving the efficiency of the housing sector. The current state system does not ensure the proper efficiency of the housing stock, which is increasingly manifested in the growing gap between the cost of operation of apartment buildings, aimed at ensuring the quality of their functioning and the real state of this quality. In recent years, numerous regulatory documents have been adopted to ensure the normal maintenance of buildings, but a comprehensive understanding of the relationship of various activities with technical and economic solutions, in most cases, has an empirical nature, not confirmed by a strict analytical justification. The purpose of the study is a systematic integrated approach to solving problems to improve the efficiency of maintenance of housing using the proposed mathematical apparatus, which allows you to objectively, fully and accurately assess the relationship of economic and technical indicators. All total socially significant economic indicators of operational measures can be the basis of legislative regulation in the industry. Conclusions: criteria for assessing the effective and safe operation of buildings, optimal for residents of apartment buildings and management companies serving these houses.
\end{abstract}

\section{Introduction}

The current state of housing remains one of the main topical problems of economic development of the Russian Federation. Numerous legislative acts aimed at improving the efficiency of housing, adopted recently, direct state financial support is not fully provide adequate change in the basic social, technical and economic indicators of this sector of the economy.

One of the main reasons for this gap is the lack of a single scientific policy that determines not individual aspects of housing development (currently mainly economic), but a set of interrelated technical, social and economic sectors in the dynamics of its development. Some attempts to solve these problems, for example, were made in relation to the operation of engineering systems of apartment buildings [1-9] and some other works. But for all housing this is clearly not enough[10]. At the same time, a number of high-tech sectors of the economy (rocket, aviation, etc.) have long developed and successfully applied theoretically sound principles of operation of the relevant facilities [11-15] and etc. The mathematical apparatus that allows to describe the mutual relationship of operational activities (repairs, maintenance, technical inspection of objects) and the technical and

*Corresponding author: sersok_07@mail.ru,vk1958@mail.ru 
economic consequences of their conduct is quite universal and, with appropriate refinement, can be successfully applied to the problems of housing. Issues of social perception of operational activities were also considered, for example, in [16,17]. On these grounds, developed some of the basic principles of effective and safe technical operation of residential buildings, discussed in this article.

\section{Materials and Methods}

The To determine the socio-economic consequences when choosing a system of repairs of apartment buildings $(\mathrm{AB})$ repairs must take into account not only the indicators that determine the technical condition of the house before and after the overhaul but also the totality of factors that will be for a very long period of time to accompany its further operation [15-17]. First of all, here we mean the inevitable occurrence of various violations that deteriorate the quality (up to the occurrence of an unacceptable risk) of the functioning of structures, engineering equipment and premises. In addition to social rejection of such violations, their elimination is associated with significant material costs. According to our data, the cost of unforeseen repairs is several times higher than the cost of major repairs. We introduce the following concept: The recovery cycle is a stochastic process between two successive regenerations.

The operational process is divided into separate, identical in content phases, which are time intervals between two successive moments of recovery (regeneration) elements. The definition of all operational events $\mathrm{Y}(\mathrm{z})$ that can occur in this time interval is a stochastic process that describes the behavior of the elements of an apartment building $(A B)$ in time. Each structural element or equipment of the engineering system has a final average operating time, culminating in a stationary recovery process, and the activities of the operational service is equally distributed over an infinitely large time period. Therefore, the set of values of the random variable $L$, which determines the duration of the regeneration cycle, and the random process $\mathrm{Y}(\mathrm{z})$, which describes the elements of the $\mathrm{AB}$ during this cycle $\{\mathrm{L},[\mathrm{Y}(\mathrm{z}), 0 \leq \mathrm{z} \leq \mathrm{L}]\}$ allows us to exhaustively represent the behavior of $\mathrm{AB}$ elements in time. This allows us to present the recovery cycle as follows (Fig. 1).

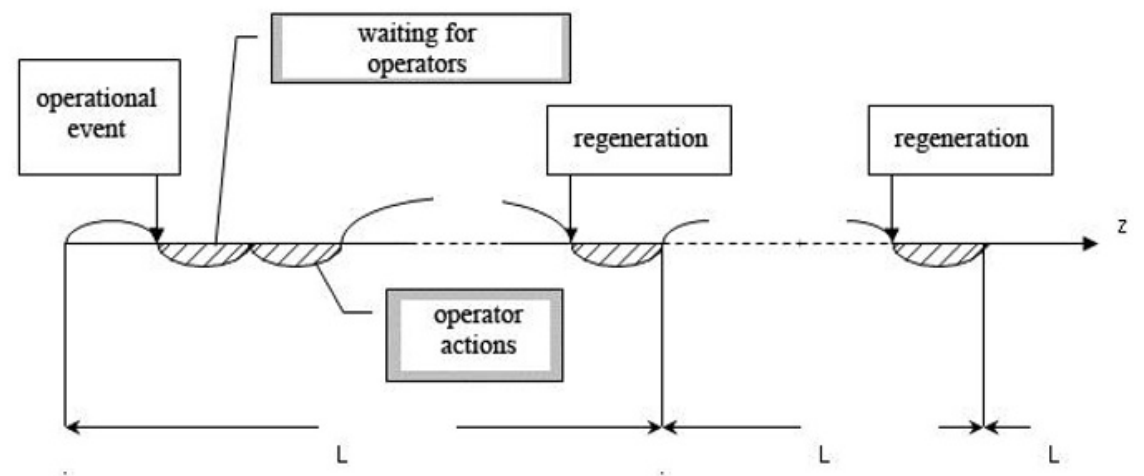

Fig.1. Reduction cycle of MCD elements.

At random times L, determined by strategic management, regeneration of the structural element (equipment) is performed. Depending on the chosen strategy, certain operational events $\mathrm{Y}(\mathrm{z})$ may occur as part of the recovery cycle, the mathematical expectation of the number of which can be determined at a given time interval using the apparatus of probability theory and recovery theory.

The definition of quality indicators - frequency of failure, the download service operation the $A B$, the complexity of the operational processes 
The obtained results related to the mathematical expectation of the duration of the recovery cycle $\mathrm{I}=\mathrm{N} / \mathrm{L}$ represent the frequency of occurrence of operational events. The total value of the frequency of occurrence of operational events will determine the frequency of calls to the operation service, and the sum of the frequency and duration of employment of the personnel of the operation service determines the complexity of all repairs and technical inspections [18-20].

Temporal evaluation of events The representation of the recovery cycle as a stochastic process allows us to make time estimates of the duration of each operational event, since the planning is necessarily assigned to the time of the beginning of the operational activities. The appointment of operator actions can be immediate, i.e. almost immediately after the occurrence of an operational event, or timed to some other planned operational event (for example, to the next technical examination or scheduled preventive maintenance). In the first case, the duration of the operational event is determined only by the operational efficiency of the service. If the moment of the beginning of operator actions is predetermined by any other factors, then the duration of the development of the operational event from the accidental moment of its occurrence should be added to the efficiency.

Relationship between operational service planning and operational efficiency The operational efficiency of the operation service depends functionally on the volume of incoming requirements for the performance of work related to operational events, and its own internal organization (operator productivity, requirements maintenance discipline, etc.). [16] The volume of claims coming into operational service, the sum of the planned activities of the regeneration system and operator actions in the event of any operating events. Both components are predetermined in strategic management, namely, the frequency of planned recovery of equipment and the frequency of occurrence and essence of operational situations in the recovery cycle.

Thus, the ergonomic properties of the object determine the direct and indirect influence of planning on the duration of the deviation of social and environmental parameters of the system from the regulated values. Direct influence is realized through the programmed time from the random moment of occurrence of an operational event to the planned term of its completion, and indirect-change of operational service (Fig.2).

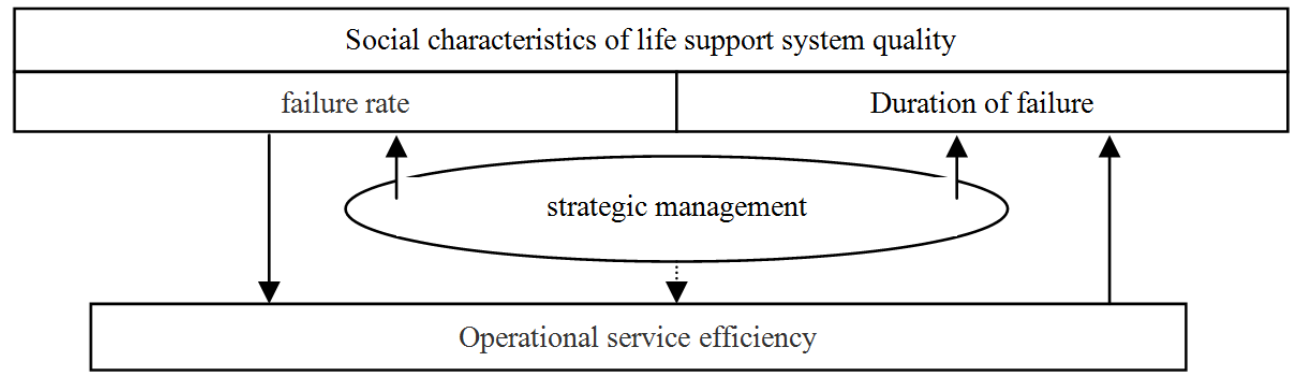

Fig.2. The scheme of direct and indirect influence of strategic management on the quality characteristics of the life support system.

Calculation of economic efficiency of the recovery cycle The economic parameters of the system are defined as a set of material and labor costs associated with the restoration work, heat and water losses in case of malfunctions in structural elements and engineering equipment, the cost of restoration of structural elements of the building and the elimination of environmental risk, compensation for damage to consumers due to the faulty state of structures and engineering systems, as well as the incomplete use of the resources of the elements of the I AB during their planned preventive replacement. 
Quantitative values of one-time and specific material costs associated with each operational event can be determined from regulatory sources or from statistical data. The material costs caused by the development of an operational event in time can be defined as the product of the duration of the operational event and the specific material costs associated with it. Then the intensity of operating costs can be defined as the ratio of the total cost to the duration of the recovery cycle:

$$
\bar{C}(\bar{R})=\frac{\sum_{i=1}^{N} C_{i}^{3}\left(R_{i}\right)+\sum_{j=1}^{M} C_{j}^{\amalg} \cdot Z_{j}(0)+C_{p e c}}{Z_{\text {ви }}}
$$

where: $\bar{C}(\bar{R})$ is the intensity of the material (labour) costs; $C_{i}^{k}\left(R_{i}\right)$ - one-time material (labor) costs associated with the $i$-th operational activities; $C_{j}^{\amalg-~ s p e c i f i c ~ m a t e r i a l ~ c o s t s ~(c o s t s ~ p e r ~}$ unit of time) associated with the $\mathrm{j}$-m faulty condition or downtime of the element;

$Z_{j}$ - duration of the j-th faulty state or idle state;

$N$ - number of operational activities of all types during the recovery cycle;

$M$ - the number of downtime and faulty States of the element during the recovery cycle. $C_{p e c}$ - costs associated with the incomplete use of the resource elements in the planned preventive replacement.

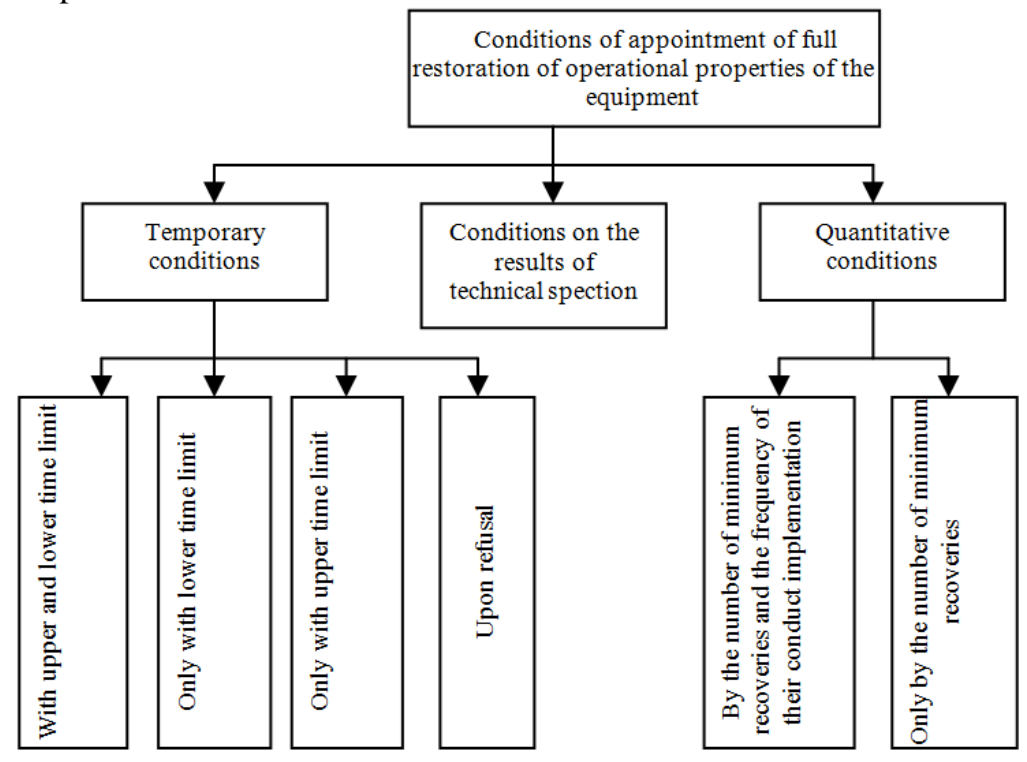

Fig. 3. Scheme of variants of regeneration conditions of the object depending on the operational events.

Calculation of the number of operational events. The expected number of events related to appearance, eat, bounce in a random time interval $\mathrm{Z}_{\mathrm{t}} \in\left[\mathrm{z}_{1} ; \mathrm{z}_{2}\right]$ depends of the reporting period and the chosen recovery strategy. In the simplest case, when the restoration of elements is provided only at a fixed time zвос (for example, according to the results of technical expertise), the number of failures for the period of regeneration is equal to one.

If during the regeneration period the minimum recovery is provided, the mathematical expectation of the number of failures for the regeneration cycle $\mathrm{Zt}$ is equal to the so-called accumulated failure rate of $\Lambda \mathrm{aB}(\mathrm{Zt})$ is determined: 


$$
\Lambda_{\text {aв }}\left(Z_{\mathrm{t}}\right)=\int_{0}^{Z_{\mathrm{t}}} \lambda(\mathrm{z}) \mathrm{dz}=\int_{0}^{Z_{\mathrm{t}}} 2 \alpha^{2} z d z=\alpha^{2} Z_{t}^{2} \cong 0.79 \frac{Z_{t}^{2}}{Z_{c p}^{2}}
$$

where: $\lambda(\mathrm{z})-$ is the failure rate of (2.7); Zcp - average life of the element. If a complete restoration of the element is provided during emergency repair, the number of failures in the considered time interval is determined from the solution of the so-called basic equation of recovery:

$$
\mathrm{H}\left(\mathrm{Z}_{\mathrm{t}}\right)=\mathrm{F}\left(\mathrm{Z}_{\mathrm{t}}\right)+\int_{0}^{\mathrm{Zt}} \mathrm{H}\left(\mathrm{Z}_{\mathrm{t}}-\mathrm{z}\right) \mathrm{dF}(\mathrm{z})
$$

where: $\mathrm{H}(\mathrm{Zt})$ is the number of complete recoveries for the period $\mathrm{Zt}$.

The solution of the given integral equation in an explicit form is impossible, therefore, a numerical solution is performed, the results of which, for various combinations of the $\mathrm{Zt}$ period and the average service life of the element, are given in table 1.

Table 1. The dependence of the expected number of full recoveries on the ratio of the average service

\begin{tabular}{|c|c|c|c|c|c|c|c|c|c|c|}
\hline $\begin{array}{c}\text { relation } \\
\mathrm{Z}_{\mathrm{t}} / \mathrm{Z}_{\mathrm{cp}} \\
\end{array}$ & 0.2 & 0.4 & 0.6 & 0.8 & 1.0 & 1.2 & 1.4 & 1.6 & 1.8 & 2.0 \\
\hline $\begin{array}{l}\text { Number of } \\
\text { full restores }\end{array}$ & 0.031 & 0.121 & 0.263 & 0.449 & 0.674 & 0.933 & 1.227 & 1.555 & 1.922 & 2.321 \\
\hline $\begin{array}{l}\text { Value of the } \\
\text { failover } \\
\text { function }\end{array}$ & 0.031 & 0.118 & 0.246 & 0.395 & 0.544 & 0.677 & 0.785 & 0.866 & 0.922 & 0.957 \\
\hline & & & & & & & & & & \\
\hline $\begin{array}{c}\text { relation } \\
\mathrm{Z}_{\mathrm{t}} / \mathrm{Z}_{\mathrm{cp}} \\
\end{array}$ & 2.2 & 2.5 & 2.7 & 3 & 3.2 & 3.5 & 3.7 & 4 & 4.5 & 5 \\
\hline $\begin{array}{l}\text { Number of } \\
\text { full restores }\end{array}$ & 2.767 & 3.455 & 4.004 & 4.632 & 4.921 & 5.211 & 5.212 & $5 . .22$ & 5.32 & 5.92 \\
\hline $\begin{array}{l}\text { Value of the } \\
\text { failover } \\
\text { function }\end{array}$ & 0.978 & 0.993 & 0.997 & 0.999 & 1 & 1 & 1 & 1 & 1 & 1 \\
\hline
\end{tabular}
life and the duration of the considered period.

Residual life of the element. The need to determine the residual life of the equipment is caused by the following circumstances. When an object reaches a certain age, usually correlated with any operational event, it is necessary to estimate the expected further time of its trouble-free operation, as well as quantitative indicators affecting the quality of the environment (for example, the final failure rate). First of all, such assessments are required when assigning the periodicity of planned repair and restoration work, when it is desirable to make the most of the capabilities of the elements of the AB. In addition, when performing preventive maintenance of the technological group, the residual life is a criterion for culling elements.

When Troubleshooting an emergency, the residual Resurs is one of the determining factors for determining the degree of recovery - minimal recovery or replacement. Another circumstance that requires the determination of the residual life is related to the economic justification of the operational activities. The problem is that, to date, with obvious significance, the economic aspect of the residual life is not a valid argument for the replacement of equipment. It is still widely believed that the change in the initial cost of equipment caused by wear and tear occurs according to the formula:

where: $C_{\text {нач }}$ - initial cost of the object;

$$
C_{\text {рес }}=C_{\text {нач }}-\Delta C_{\text {нач }} \cdot z
$$

$$
\Delta C_{\text {нач }}=C_{\text {нач }} / Z_{\text {норм }}
$$

where: $Z_{\text {норм }}$ - normative service life of the object; $\mathrm{z}$ - operation time of the facility; $C_{p e c}-$ costs associated with the incomplete use of the resource elements in the planned preventive replacement. 
When considering the effective choice of a building repair system, it is necessary to examine the relationship between technical and economic solutions. Currently, the decisive factor is the economic costs. To maintain or increase the durability of the building, improving the technical characteristics of structures is an important condition. Therefore, it is necessary to consider all the solutions that affect the increase in the service life of buildings. All existing normative documents on technical maintenance of buildings [1-9] were considered, as well as the work of scientists in other fields of activity, in which justified principles of operation are applied. The paper deals with the work of the Boolean algebra of Dillon b [11], Balan a O [13-14], on the reliability and stability of the buildings at all stages of the life cycle of the Trukhanov V. M., on the optimization of the reliability of the structural and complex technical systems of the Skvortsov M. S., and others. In this article, when choosing a model of repair, this mathematical apparatus was used for the system of repairs in the housing and communal sphere in the system of repairs. [7]

In accordance with the above formula, when the object reaches the age equal to the standard service life, its cost is zero. And if you exceed this age, the results of calculations by the formula become incorrect, because they take a negative value.

However, in practice, there are widespread cases when the time of exportation of $\mathrm{AB}$ elements reaches and exceeds the normative service life and, at the same time, they remain in good condition and perform their functions. This phenomenon suggests that the elements of the $\mathrm{AB}$, regardless of age, has some residual value of the $\mathrm{Co}$, which varies in proportion to the operating time and can be represented by the following expression:

$$
\mathrm{Co}=\mathrm{C} \frac{\mathrm{Zo}}{\mathrm{Zcp}}
$$

where: $\mathrm{C}$ - initial cost of equipment or item, $Z_{o c m}$ and $Z_{c p}$ respectively the residual and the average lifespan of the equipment.

\section{Results and Discussion}

The use of the residual life of the $\mathrm{AB}$ element leads to the period of its decommissioning and, accordingly, the time of installation of a new one. Thus, there is a "delay" in the need for investment of material resources associated with the installation of a new element, which can be economically assessed as follows. It is known that the promising material investments, which are the costs of replacing the elements of the $\mathrm{AB}$, are converted to the time from which the analysis is carried out, according to the following formula:

$$
\mathrm{C}(\text { Zнач })=\frac{\mathrm{C}\left(\mathrm{Z}_{\text {paсч }}\right)}{(1+v)^{Z_{\text {per }}}}
$$

where: $\mathrm{C}($ Zнач $)$ - reduced costs; C (Zрасч) - funds allocated at the estimated time Zpacч; v-interest rate determined, for example, by the Central Bank.

Suppose that the planned replacement is scheduled at the time of the Zпл (Fig. 3). If a failure has not occurred by the appointed time, there is a certain residual life of the ZocT equipment. Suppose you have the opportunity to continue the operation of the element of the $\mathrm{AB}$ to the IP-digging resource. Then, the cost of restoration, given to the initial appointed time of scheduled maintenance, will be:

$$
\operatorname{Cвосcт}\left(Z_{\text {nII }}\right)=\frac{C_{\text {раст }}^{\text {восст }}}{(1+v)^{\text {Zocr }}}
$$

where: $\mathrm{C}_{\text {pac4 }}^{\mathrm{Bocc}}$ - estimated cost of the replacement item $\mathrm{AB}$.

The economic benefit from the postponement of the recovery period will be:

$$
\ni=C_{\text {pacr }}^{\text {вocr }}\left(1-\frac{1}{(1+v)^{Z_{\text {oct }}}}\right)
$$




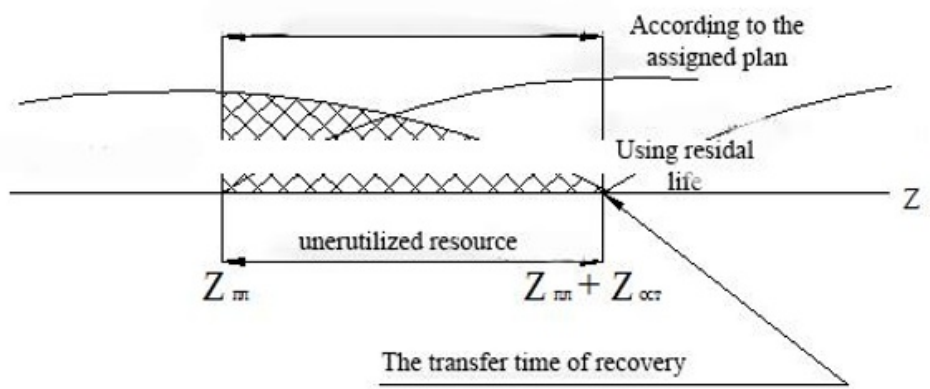

Fig. 4. Representation of dependencies of underutilized resource and gain in capital investments on the residual resource of the object.

Based on the foregoing, the total economic impact (or costs CI when not using) the residual resource of the equipment will be part lyat:

$$
\mathrm{C}_{\text {рес }}=\mathrm{C}_{\text {элемента }} \frac{\mathrm{Z}_{\text {ост }}}{\mathrm{Z}_{\mathrm{cp}}}+\mathrm{C}_{\text {раст }}^{\text {вост }}\left(1-\frac{1}{(1+v)^{Z_{\text {ост }}}}\right)
$$

where: $\mathrm{C}_{\text {элемента }}$ - estimated cost of item $\mathrm{AB} ; \mathrm{Z}_{\text {ост }}$ and $\mathrm{Z}_{\mathrm{cp}}$ respectively the residual and the average lifespan of the equipment; $\mathrm{C}_{\text {расч }}^{\text {Восст }}$ estimated cost of the replacement item $A B ; v$ interest rate determined

\section{Conclusions}

The considered mathematical models of the relationship of operational activities with the technical, social and economic consequences of their implementation allow to perform a long-term forecast of the efficiency of housing development at the level of legislative and Executive state bodies.

The proposed possibility of assessing the frequency of unfavorable situations for users of apartment buildings, functionally associated with the material costs of the possibility of its change to a significant extent allows to remove the misunderstanding between residents of houses and management companies and, at the same time, to strengthen control over the efficiency of production activities of the latter.

The proposed criteria for assessing the effective and safe operation of apartment buildings, taking into account the unambiguously perceived by the residents of houses and representatives of management companies indicators of the quality of operation and, at the same time, all the total socially significant economic indicators of operational activities can be the basis of new legislative regulation in the industry.

\section{References}

1. GOST R 56194-2014 Services of housing and communal services and management of apartment buildings. Services of technical inspections of apartment buildings and determination on their basis of the work plan, the list of works. General requirements.

2. GOST R 56037-2014 services of housing and communal services and management of apartment buildings. Dispatching and emergency repair services. General requirements.

3. GOST R 56038-2014 Services of housing and communal services and management of apartment buildings. Management services of apartment buildings. General requirements. 
4. Set of rules SP 255.1325800.2016 " Buildings and structures. Operating rules. General provisions.

5. GOST R 56192-2014 Services of housing and communal services and management of apartment buildings. Services of maintenance of common property of apartment buildings. General requirements.

6. Korol, E.A., Kustikova, Y.O. Constructive systems, load-bearing and enclosing structures of high-rise buildings. E3S Web of Conference 2018.

7. Borkovskaya V.G. Project Management Risks in the Sphere of Housing and Communal Services. Journal MATEC Web of Conferences, Volume 251, 06025 (2018). DOI: https://doi.org/10.1051/matecconf/201825106025.

8. Korol O., Shushunova N., Lopatkin D., Zanin A., Shushunova T. Application of Hightech Solutions in Ecodevelopment. Journal MATEC Web of Conferences, Volume 251, 06025 (2018). DOI: https://doi.org/10.1051/matecconf/201825106002

9. Korol E.A., Gaydysheva Y., Passmore D. Integration of organizational-technological and social aspects in the realization of the program of renovation of residential development. Journal MATEC Web of Conferences, Volume 251, 06025 (2018). DOI: https://doi.org/10.1051/matecconf/201825106025

10. Kalinin V M 2008 Assessment of reliability and prediction of longevity no 7 pp 55-58.

11. Dillon B, Singkh C H 1984 Engineering methods for ensuring the reliability of systems (Moscow: World) pp 51-104.

12. Borkovskaya V.G. Complex models of active control systems at the modern developing enterprises. Advanced Materials Research (Volumes 945-949). Chapter 22: Manufacturing Management and Engineering Management. June 2014. Pages 30123015. DOI: 10.4028/www.scientific.net/AMR.945-949.3012.

13. Balan A O 2003 An Enhanced Approach to Network Reliability Using Boolean Algebra (AnHonors Thesis presented to the Departments of Computer Science and Mathematics of Lafayette College) pp 1-43.

14. Balan A O, Traldi L 2003 Preprocessing Minpath for Sum of Products (IEEE Trans. Reliability) vol R-52 no 3 pp 289-294.

15. Borkovskaya V.G. Complex models of active control systems at the modern developing enterprises. Advanced Materials Research (Volumes 945-949). Chapter 22: Manufacturing Management and Engineering Management. June 2014. Pages 30123015. DOI: 10.4028/www.scientific.net/AMR.945-949.3012

16. Borkovskaya V, Passmore D. Application of Failure Mode and Effects Analysis in Ecology in Russia. MATEC Web of Conf., 193 (2018) 05027. DOI: https://doi.org/10.1051/matecconf/201819305026.

17. Roe R., Bardenwerper W, Borkovskaya V.G. Using a Case Study Interactively to teach Sustainability Risk Management. Journal MATEC Web of Conferences, Volume 251, 06028 (2018). DOI: https://doi.org/10.1051/matecconf/201825106028.

18. Polyakova V., Degaev E.,Pierre El Haddad. Reduction of Ecological and Economic Risks in Utilization of Solid Domestic Wastes and Construction Waste. MATEC Web of Conferences 251, 06017 (2018). https://doi.org/10.1051/matecconf/201825106017.

19. Degaev E.N. New classification of Foaming Agents for Fire Extinguishing. MATEC Web of Conferences. 193, 02032 (2018). DOI: https://doi.org/10.1051/matecconf/201819302032.

20. Degaev E., Orlov A., Pierre El Haddad, Pleshivtsev A. Ecological and Economic Risks of Fire Protection of Warehouses and Tank Parks. MATEC Web of Conferences. 251, 06013 (2018).DOI: https://doi.org/10.1051/matecconf/201825106013. 